\title{
Morbidity and Mortality Profile of Late Preterm Neonates as Compared to Term Neonates from a Tertiary Care Centre in Silchar
}

\author{
Pranav N. Saji ${ }^{1}$, Anupama Deka² \\ ${ }^{1,2}$ Department of Pediatrics, Silchar Medical College and Hospital, Masimpur, Silchar, Assam, India.
}

\section{ABSTRACT}

\section{BACKGROUND}

Late preterm infants are less mature physiologically and have poor compensatory responses when compared to term infants. Recent studies have implied increased morbidities in late preterm infants and higher rate of hospital admission during neonatal period. Multiple maternal risk factors lead to the increasing incidence of late preterm births. We wanted to study the morbidity and mortality profile of late preterm infants compared to term infants.

\section{METHODS}

The study was conducted in the special newborn care unit (SCNU) of Silchar Medical College and Hospital. The study population comprised of 175 late preterm and 175 term babies admitted in SCNU. It was a cross sectional study.

\section{RESULTS}

In this study 175 late preterm neonates were compared with 175 term neonates. Late preterm babies were at increased risk of hypoglycemia $(P$ value $=0.0130)$, neonatal jaundice $(\mathrm{P}=0.021)$, culture positive sepsis $(\mathrm{P}=0.001)$, respiratory distress $(\mathrm{P}=$ $0.000)$, hypocalcaemia $(\mathrm{P}=0.030)$, difficulty in feeding $(\mathrm{P}=0.000)$ and birth asphyxia $(P=0.013)$, longer hospital stay and mortality $(P=0.009)$ when compared to term babies. In babies of mothers with oligohydramnios and pregnancy induced hypertension, preterm babies had significant morbidity compared to term babies.

\section{CONCLUSIONS}

Late preterm babies have an increased risk of morbidity and mortality when compared to term neonates and need special care. Premature rupture of membranes, antepartum hemorrhage and pre-eclampsia are the main maternal complications leading to premature delivery of the baby.

\section{KEY WORDS}

Late Preterm, Preeclampsia, Oligohydramnios, Morbidity
Corresponding Author:

Dr. Anupama Deka,

Department of Pediatrics,

Silchar Medical College and

Hospital, Masimpur, Silchar,

Assam, India,

E-mail: anupamadeka-100@gmail.com

DOI: $10.14260 /$ jemds/2021/458

How to Cite This Article:

Saji PN, Deka A. Morbidity and mortality profile of late preterm neonates as compared to term neonates from a tertiary care centre in Silchar. J Evolution Med Dent Sci 2021;10(30):2239-2243, DOI: $10.14260 /$ jemds/2021/458

Submission 27-01-2021, Peer Review 21-05-2021, Acceptance 27-05-2021, Published 26-07-2021.

Copyright (C) 2021 Pranav N. Saji et al. This is an open access article distributed under Creative Commons Attribution License [Attribution 4.0 International (CC BY 4.0)] 


\section{BACKGROUND}

Late preterm babies are those babies whose period of gestation is between 340 / 7 to 366 / 7 weeks. These babies physiological maturity is less compared to term babies. Although these babies were considered as near term in the past, newer studies from western nations show that they have limited compensatory responses to the extrauterine environment. ${ }^{1}$ Late - preterm neonates are more susceptible to problems concerning immaturity and delayed transition. Therefore these babies require special consideration compared to term babies and are treated differently. ${ }^{2}$ It is also evident that as the gestational age of the baby increases chances of developing complications markedly decrease along with less duration of hospital stay and less mortality.

The obstetric and newborn care of western countries is different from a developing country like India. Most often late preterm babies are managed same as that of term infants. They are loosely termed as "near term" infants and assumed to do well and behave like term neonates in the immediate postnatal period. Limited studies are conducted in India regarding the early morbidities of late preterm babies when compared to term babies. Thus, there was a need to conduct this study, which deals with the problems of late preterm infants. 3,4 Reduced compensatory responses to the extra-uterine environment is noticed in the late preterm babies, which constitute the majority of preterm babies. In literature a huge list of complications pertaining mainly to preterm babies can be seen relating to almost all systems of the body and it can be a benign lesion like transient tachypnoea of newborn (TTNB) to dangerous morbidities like respiratory distress syndrome, hypothermia, pulmonary hypertension, apnea, hypocalcemia, perinatal asphyxia, clinical sepsis, culture proven sepsis, feed intolerance hypoglycaemia and neonatal jaundice.

Late preterm babies are more susceptible to admission in neonatal intensive care unit (NICU), long duration of hospital stay and repeated admission in hospitals compared to the term babies. These morbidities at the time of birth can have influence across the life course of the late preterm babies and recent studies have seen long-term morbidities including the neurocognitive and emotional problems that can occur during childhood and adulthood. Morbidities can be anticipated in these late preterm babies and proper care and treatment should be given if health workers are aware of these morbidities and thus mortality can be reduced. ${ }^{5}$ Because of these increased morbidities and increased mortality of late preterms, widespread practice of induction of labour and / or elective caesarean sections for preterm babies should be controlled. Many studies have shown that premature rupture of membranes, antepartum haemorrhage, oligohydramnios and preeclampsia are the most important maternal factors identified for premature delivery.

This study intended to find out the morbidity and mortality of late preterm babies compared to the term neonates along with the maternal risk factors which lead to the premature delivery of the baby.

\section{METHODS}

This was a cross sectional study conducted at Silchar medical college and hospital, India from September 2019 to April 2020. This is a tertiary care hospital. Late preterm neonates born between $340 / 7$ and $366 / 7$ weeks of gestation in hospital were compared with term neonates (37 0 / 7 to 416 / 7 weeks gestation) born in Silchar hospital. Consent was obtained from the parents of all neonates included for the study and the study was approved by the institutional ethical committee. Sample size was calculated using the formula $\mathrm{n}=\mathrm{Z}^{2} \mathrm{pq} / \mathrm{d} 2$, where $\mathrm{z}=$ $1.96, p=$ prevalence of late preterm infants in Silchar medical college and hospital as per the previous records, $q=(1-p), d$ = $95 \%$ confidence interval. Sample calculated by using the above formula was 175 . A total of 175 late preterm and 175 term neonates were included in the study group.

Gestational assessment was done by using dating scan between $6-12$ weeks. In the absence of which, the gestation was calculated from the LMP and clinical confirmation of gestation by expanded New Ballard Score. The enrolled babies were divided into two groups as follows. In those infants who were admitted to special care units other than well baby nursery, their maternal obstetrical factors and neonatal morbidities developed were collected.

\section{Inclusion Criteria}

Gestational age 340 / 7 to 366 / 7 weeks. Equal number of term (between 37 weeks of gestation and 42 weeks of gestation) babies born in Silchar hospital, during the study period.

\section{Exclusion Criteria}

Neonates having major anomalies and clinically identifiable chromosomal syndromes were not included in the study. Detailed antenatal history along with pregnancy related complications developed during the antenatal period was collected along with detailed natal history which lead to premature delivery of the baby. All the neonates admitted in SCNU were examined twice a day and the complications developed were noted.

\section{Statistical Analysis}

Statistical methods (descriptive studies, chi square test, and independent sample $t$ - test) were carried out through the SPSS for windows version 16.0. The $P$ value value $<0.05$ was taken as significant.

\section{RESULTS}

The study group included live born neonates delivered in Silchar medical college and hospital, India. Total live births during the study period were 1023, including 761 term and 190 preterm infants. Out of total preterm babies there were $175(61.3 \%)$ infants born after 34 weeks of gestation. 
In the present study a total of 175 late preterm neonates were compared with 175 term neonates. There were 57 neonates between 34 to $34(6 / 7)$ weeks gestation, 57 neonates between 35 to $36(6 / 7)$ weeks gestation and 61 neonates between 36 to $36(6 / 7)$ weeks gestation.

\begin{tabular}{|ccc|}
\hline $\begin{array}{c}\text { Gestational Age } \\
\text { Weeks (Days) }\end{array}$ & $\begin{array}{c}\text { Number of Late } \\
\text { Preterms (N = 175) }\end{array}$ & Percentage \\
\hline $34-34(6 / 7)$ & 57 & 40 \\
$35-35(6 / 7)$ & 57 & 30.8 \\
$36-36(6 / 7)$ & 61 & 29.2 \\
\hline \multicolumn{2}{|c|}{ Table 1. Gestational Age of Late Preterm Babies in the Study Group } \\
\hline
\end{tabular}

The risk factors for preterm deliveries were prolonged rupture of membranes (35 cases), pregnancy induced hypertension (10 cases), antepartum haemorrhage (8 cases) oligohydramnios ( 5 cases), uterine malformations in one case and idiopathic in rest of the cases. In this subset of new borns, late preterm infants were more likely to be delivered by caesarean section than term infants $(\mathrm{P}<0.001)$.

\begin{tabular}{|ccc|}
\hline Variables & No. of Delivery & Percentage \\
$\begin{array}{c}\text { Prolonged rupture of } \\
\text { membranes }\end{array}$ & 35 & 20 \\
Pregnancy induced & 10 & 5.7 \\
hypertension & 8 & 4.5 \\
Antepartum hemorrhage & 5 & 2.8 \\
Oligohydramnios & 1 & 0.57 \\
Uterine malformation & 116 & 66.2 \\
\hline No risk factors & Table. 2 Risk Factors of Mothers for Premature Delivery \\
\hline
\end{tabular}

About $28 \%$ of late preterm neonates had difficulty in establishing feeding at birth and needed feeding given by pallada feeds or nasogastric tube feeding as compared to only $8.5 \%$ of term neonates. Later on babies who developed feed intolerance were also included here and was statistically significant. 64 preterm neonates had respiratory distress at birth as compared to 22 term neonates ( $\mathrm{P}$ value $<0.000$ ).

It was found that as gestational age decreases respiratory distress increases even in late preterm groups. 43 babies had
TTNB, respiratory distress syndrome (RDS) (12 babies), pneumonia (7 babies), pneumothorax and pulmonary haemorrhage one case each. In term babies 12 cases of TTNB, 10 cases of macrophage activation syndrome (MAS) and 2 cases of pneumonia were found.

Hypocalcaemia and hypoglycaemia were also found to be significantly high in preterms when compared with the term babies. $17 \%$ of preterm babies suffered from hypocalcaemia compared to $6 \%$ term babies. These metabolic complications were mainly noticed in children who had suffered from feeding difficulties and temperature instability and culture proven sepsis neonates. Late preterm babies born between 34 weeks to 346 / 7 weeks were found to have higher incidence of morbidities compared to late preterms born from 35 weeks onwards. Higher incidence of birth asphyxia (P - Value: 0.0102 ) and feeding difficulty (0.0057) were found in babies born between 34 weeks to 346 / 7 weeks compared to other preterm babies. Late preterm infants were more prone to have culture proven sepsis than term infants, but the significant difference was noticed only in late - onset (P value $<0.0427$ ) and not early - onset sepsis.

About $26.8 \%$ of late preterm neonates had jaundice requiring intervention in the form of phototherapy or exchange transfusion as against $9.7 \%$ of term neonates which were statistically significant. Incidence of intraventricular haemorrhage and neonatal necrotizing enterocolitis was much lower in our study. Incidence of hypothermia was very common among late preterm neonates (37 neonates) as compared to term neonates ( 8 neonates) which was found to be significant. The duration of stay in hospital was significantly more in late preterm infants as compared to term neonates (6.3 versus 3.9 days). Most important was the mortality which was significantly more among late preterm neonates $(7.4 \%)$ as compared to term neonates. Out of 175 preterm babies admitted, 13 mortalities occurred. Out of 13 deaths, 8 babies died due to perinatal asphyxia, which became the major cause of mortality.

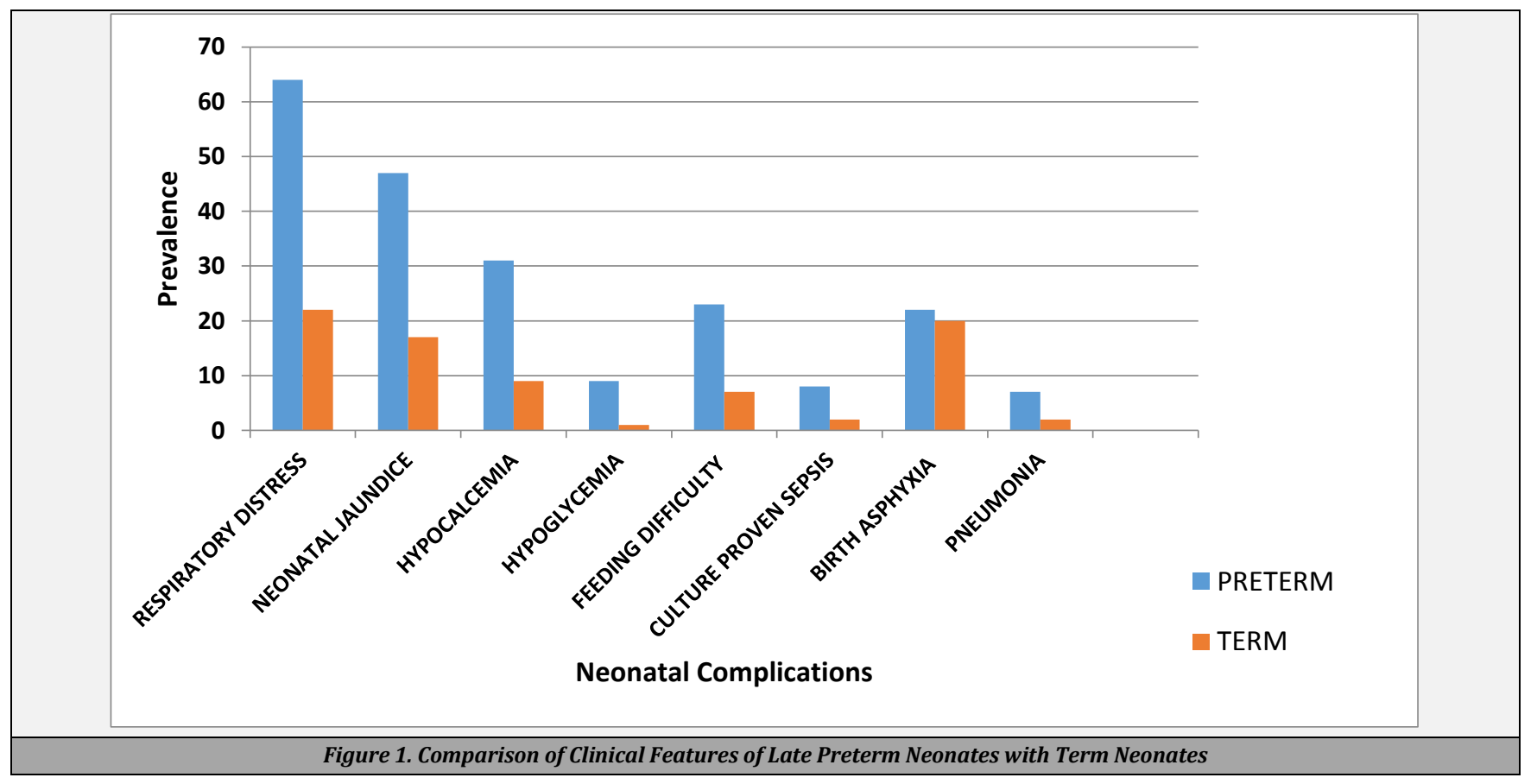




\begin{tabular}{|cccccc|}
\hline Risk Factor & $\begin{array}{c}\text { No. of } \\
\text { Preterm } \\
\text { Delivery }\end{array}$ & $\begin{array}{c}\text { No. of } \\
\text { Preterm } \\
\text { Death }\end{array}$ & $\begin{array}{c}\text { No. of } \\
\text { Term } \\
\text { Delivery }\end{array}$ & $\begin{array}{c}\text { No. of } \\
\text { Term } \\
\text { Death }\end{array}$ & P - Value \\
\hline Prom & 35 & 2 & 21 & 1 & 0.8782 \\
PIH & 12 & 4 & 20 & 1 & 0.0325 \\
APH & 5 & 0 & 9 & 0 & - \\
Oligohydramnios & 5 & 3 & 14 & 1 & 0.0128 \\
Uterine & 1 & 0 & 0 & 0 & - \\
Malformation & 117 & 4 & 111 & 1 & 0.1944 \\
No Risk Factor & Table 4. Comparison of Risk Factors of \\
\hline \multicolumn{5}{c}{ Mother and Cause of Death in Neonates } \\
\hline
\end{tabular}

3 babies died because of sepsis and 2 babies died because of intraventricular haemorrhage (IVH). 4 babies out of 175 expired in term neonates. All the 4 babies died due to perinatal asphyxia. In babies of mothers with oligohydramnios and pregnancy induced hypertension, preterms had significant morbidity compared to term babies while babies of mothers with premature rupture of membranes and antepartum haemorrhage did not find any significant morbidity compared to term babies.

\begin{tabular}{|c|c|c|c|c|c|c|}
\hline Variables & $\begin{array}{c}\text { 34 Wks } \\
\text { N }=57\end{array}$ & $\begin{array}{c}35 \text { Wks } \\
N=57\end{array}$ & $\begin{array}{c}36 \text { Wks } \\
N=61\end{array}$ & $\begin{array}{c}\text { Total } \\
175\end{array}$ & $\begin{array}{c}\text { Term } \\
175\end{array}$ & $\begin{array}{c}\text { P - } \\
\text { Value }\end{array}$ \\
\hline $\begin{array}{l}\text { Respiratory } \\
\text { distress }\end{array}$ & 32 & 18 & 14 & 64 & 22 & 0.0000 \\
\hline Neonatal jaundice & 21 & 20 & 6 & 47 & 17 & 0.0000 \\
\hline Hypocalcemia & 18 & 10 & 3 & 31 & 9 & 0.0004 \\
\hline Hypoglycaemia & 4 & 3 & 2 & 9 & 1 & 0.0247 \\
\hline IVH & 4 & 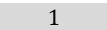 & 0 & 5 & 1 & 0.2166 \\
\hline Feeding difficulty & 15 & 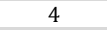 & 4 & 23 & 7 & 0.00418 \\
\hline Pneumonia & 1 & 3 & 3 & 7 & 2 & 0.1791 \\
\hline $\begin{array}{l}\text { Culture proven } \\
\text { sepsis }\end{array}$ & 4 & 1 & 5 & 10 & 2 & 0.0397 \\
\hline Early onset sepsis & 1 & 0 & 1 & 2 & 1 & 0.562 \\
\hline Late onset sepsis & 4 & 2 & 2 & 8 & 1 & 0.0427 \\
\hline Birth asphyxia & 14 & 4 & 4 & 22 & 20 & 0.8693 \\
\hline PDA & 3 & 0 & 0 & 3 & 0 & 0.0121 \\
\hline Death & 8 & 3 & 2 & 13 & 3 & 0.0212 \\
\hline $\begin{array}{l}\text { Duration of } \\
\text { hospital stay }\end{array}$ & $\begin{array}{c}7.047+/- \\
4.142\end{array}$ & $\begin{array}{c}6.523+/- \\
3.6754\end{array}$ & $\begin{array}{c}6.147+/- \\
5231\end{array}$ & $\begin{array}{l}6.3182+ \\
/-4.255\end{array}$ & $\begin{array}{c}3.917+/ \\
2.165\end{array}$ & 0.000 \\
\hline
\end{tabular}

\section{DISCUSSION}

Late preterm babies suffer significant morbidity and mortality when compared to term neonates and the belief that late preterm infants are nearly term babies has changed following the study. A total of 175 late preterms and equal number of term babies were studied during the study period. Among preterm babies $38 \%$ were females and males constituted 62 $\%$ which was almost similar to the observation made by Jaiswal A et al. ${ }^{1}$ Khashu $\mathrm{M}$ et al. and Sahana et al.6,7 studies showed that most common risk factors for late preterm deliveries were prolonged rupture of membranes, oligohydramnios, antepartum haemorrhage and pregnancy induced hypertension. Same risk factors were identified in our study.

By comparing the studies done by Gouyon $\mathrm{BJ}^{8}$ it was seen that total number of late preterm babies born by caesarean section was much higher in the present study which constituted $52.8 \%$. Respiratory distress was significantly more common amongst late preterm neonates in the present study. Similar results were obtained by Sahana et al. ${ }^{7}$ This may be due to delayed fluid clearance from the lungs immediately following delivery and surfactant deficiency, increased incidence of TTNB in our study secondary to the high rate of LSCS. ${ }^{9}$
Significantly a higher number of late preterm neonates had jaundice requiring phototherapy or exchange transfusion than term neonates. Similar results were obtained by Jaiswal A et al. ${ }^{1}$ This may be because of feeding difficulties of the preterm babies and developmental immaturity of the liver leading to decreased enzyme activity and decreased life span of RBCs in preterm babies. Death in late preterms in the present study was $7.4 \%$ and $1.7 \%$ term babies and statistically mortality was found significant in late preterms $(\mathrm{P}<0.05)$. Celik IH et al. ${ }^{10}$ also found similar results in mortality. The overall duration of stay amongst late preterm neonates was twice that of term neonates in the present study thus, adding a burden to health care resources. Hence, considering that late preterms are more prone for morbidity and mortality, clinicians should closely monitor late preterms immediately after birth and also, obstetricians should use this information in weighing the risks and benefits of late preterm babies. Most common cause of mortality in our study was perinatal asphyxia. It accounted for $10.6 \%, 26.2 \%$ and $26 \%$ of perinatal mortalities in studies conducted in Maharashtra, ${ }^{11}$ Orissa $^{12}$ and West Bengal ${ }^{13}$ respectively. In the present study $69 \%$ mortality was due to birth asphyxia.

In the present study late preterms had more feeding difficulties with need for nutritional and supportive management as compared to term neonates. Late preterm infants have poorer peristalsis and sphincter controls. ${ }^{14}$ They are less able to achieve effective sucking and swallowing. ${ }^{15}$ This often leads to delay in establishing feeds and results in poor weight gain. They also have immature GI function. ${ }^{16}$ Ming - Luen Tsai ${ }^{17}$ studies show higher incidence of culture positive sepsis in preterm babies but significant difference $[P$ - value: $0.042]$ is seen only for late onset sepsis. In the present study the incidence of sepsis was $8.6 \%$ in late preterm neonates as compared to $1.8 \%$ in term neonates. Similar incidence of 10.3 \% versus $1.37 \%$ was found in a similar South Indian study by Sahana et al. ${ }^{7}$ Jaiswal A et al. ${ }^{1}$ concluded that late preterms are at 3.2 times higher risk of probable sepsis as compared to term neonates. In the present study the mortality in late preterms was also significantly higher than term neonates.

\section{CONCLUSIONS}

Premature rupture of membranes, antepartum haemorrhage and preeclampsia are the most important maternal factors identified for premature delivery. Respiratory distress, feeding difficulties, birth asphyxia, late onset sepsis and neonatal hyperbilirubinemia are the most common morbidities detected in this study. A large group of late preterm babies in the study group required ICU admission for some morbidity which developed immediately during the post natal period and, hence all these vulnerable groups should be closely monitored till the baby is shifted to the maternal side. Therefore iatrogenic late preterm births should be reduced as much as possible so that morbidities of late preterm babies which can even lead to some chronic diseases can be prevented. In babies of mothers with oligohydramnios and pregnancy induced hypertension, preterms had significant morbidity compared to term babies while babies of mothers with premature rupture of membranes and antepartum 
haemorrhage did not find any significant morbidity compared to term babies.

Data sharing statement provided by the authors is available with the full text of this article at jemds.com.

Financial or other competing interests: None.

Disclosure forms provided by the authors are available with the full text of this article at jemds.com.

\section{REFERENCES}

[1] Jaiswal A, Murki S, Gaddam P, et al. Early neonatal morbidities in late preterm infants. Indian Pediatr 2011;48(8):607-11.

[2] Jain L. Morbidity and mortality in late-preterm infants: more than just transient tachypnea! J Pediatr 2007;151(5):445-6.

[3] Wagh AS, Tewari VV, Jain DMN. Comparison of neonatal morbidities of late preterm with term born babies. Sepsis (CRP> $10 \mathrm{mg} / \mathrm{L}$ ) 2012;114:104.

[4] Savitha MR, Sanjee SS. Morbidity and mortality profile of late preterm neonates as compared to term neonates from a tertiary care centre in Mysore, India. International Journal of Contemporary Pediatrics 2016;3(1):164.

[5] Wang ML, Dorer DJ, Fleming MP, et al. Clinical outcomes of nearterm infants. Pediatrics 2004;114(2):372-6.

[6] Khashu M, Narayanan M, Bhargava S, et al. Perinatal outcomes associated with preterm birth at 33 to 36 weeks gestation: a population-based cohort study. Pediatrics 2009:123(1):109-13.
[7] Sahana, Adarsh E, Sunil, et al. Short term outcome of late preterms. IJAMS 2014;3(1):205-11.

[8] Gouyon JB, Vintejoux A, Sagot P, et al. Neonatal outcome associated with singleton birth at 34-41 weeks of gestation. Int J Epidemiol 2010;39(3):769-76.

[9] Leone A, Ersfeld P, Adams M, et al. Neonatal morbidity in singleton late preterm infants compared with full term infants. Acta Paediatr 2012;101(1):6-10.

[10] Celik IH, Demirel G, Canpolat FE, et al. A common problem for neonatal intensive care units: late preterm infants, a prospective study with term controls in a large perinatal center. J Matern Fetal Neonatal Med 2013;26(5):459-62.

[11] Park K. Park's textbook of preventive and social medicine. Chap. 10. 21 $1^{\text {st }}$ edn. Preventive Medicine in Obstetrics, Paediatrics and Geriatrics. Banarsidas Bhanot, Jabalpur India: 2009:481-560.

[12] Salam A, Akhtar MS. Perinatal mortality in Bijapur city, Karnataka: one year hospital study. Indian J Comm Health 1998 \& 1999;4(2) \& 5(1):18-24.

[13] Paul DK, Bag T. Perinatal mortality in rural medical college of West Bengal. Indian J Public Health 2005;49(4):240.

[14] Neu J. Gastrointestinal maturation and feeding. Semin Perinatol 2006;30(2):77-80.

[15] Adamkin DH. Feeding problems in the late preterm infant. Clin Perinatol 2006;33(4):831-7.

[16] Al Tawil Y, Berseth CL. Gestational and postnatal maturation of duodenal motor responses to intragastric feeding. J Pediatr 1996;129(3):374-81.

[17] Tsai ML, Lien R, Chiang MC, et al. Prevalence and morbidity of late preterm infants: current status in a medical center of Northern Taiwan. Pediatr Neonatol 2012;53(3):171-7. 